\title{
Policy statement on folic acid and neural tube defects
}

\author{
Helga V. Toriello, PhD, for the Policy and Practice Guideline Committee of the American College of \\ Medical Genetics
}

\begin{abstract}
Disclaimer: ACMG standards and guidelines are designed primarily as an educational resource for medical geneticists and other healthcare providers to help them provide quality medical genetic services. Adherence to these standards and guidelines does not necessarily ensure a successful medical outcome. These standards and guidelines should not be considered inclusive of all proper procedures and tests or exclusive of other procedures and tests that are reasonably directed to obtaining the same results. In determining the propriety of any specific procedure or test, the geneticists should apply their own professional judgment to the specific clinical circumstances presented by the individual patient or specimen. It may be prudent, however, to document in the patient's record the rationale for any significant deviation from these standards and guidelines.
\end{abstract}

\begin{abstract}
It now recognized that the use of folate fortification and/or supplementation before initiation of pregnancy can impact the risk of the fetus developing a neural tube defect. This document serves to update the policy statement issued by the American College of Medical Genetics and published in 2005. Genet Med 2011:13(6):593-596.
\end{abstract}

Key Words: supplementation, fortification, prevention

$\mathrm{N}$ eural tube defects (NTDs) are a group of serious birth defects that affect the developing nervous system and include anencephaly, spina bifida, and encephalocele. In anencephaly, there is partial or complete absence of the skull bones with minimal remnant of brain; it is almost always fatal before or shortly after birth. Spina bifida results from the failure of the vertebral arches to close over an open neural tube, exposing the spinal cord and nerves. Spina bifida is compatible with survival, although physical and occasional cognitive impairment occurs. With encephalocele, there is protrusion of the brain and/or its covering membranes through the skull, most often in the occipital region. The birth frequency of NTDs varies among countries and regions within countries but in general is said to be approximately $1 / 1000$. At least $90 \%$ of NTDs occur to women without a family history of this disorder. NTDs occur within 1 month of conception.

Since the 1970s, maternal nutrition, particularly regarding folate, has been linked to the occurrence of NTDs. Folate is the generic term for one of the B-complex vitamins that serves an essential role in the metabolism of nucleic and amino acids. It occurs in certain foods as polyglutamate, a form that is less easily absorbed than free folate. Folic acid is the oxidized and most active form but is rarely found in food. This is the form

From the Spectrum Health Hospitals and College of Medicine, Michigan State University, Grand Rapids, Michigan.

Helga V. Toriello, PhD, Spectrum Health Hospitals and College of Medicine, Michigan State University, 25 Michigan Street, Suite 2000, Grand Rapids, MI 49503. E-mail: helga.toriello@spectrum-health.org.

Disclosure: The authors declare no conflict of interest

Approved by the ACMG Board of Directors March 24, 2010.

Published online ahead of print May 5, 2011.

DOI: $10.1097 /$ GIM.0b013e31821d4188 used in vitamin preparations and food fortification. Folic acid is almost twice as bioavailable as folate. Through a series of steps, folate or folic acid are converted to 5-methyltetrahydrofolate, which is the primary circulating form of folate and which can be transported into the cell via folate receptors.

Smithells et al. ${ }^{1}$ found that lower levels of folate and vitamin C were associated with a higher frequency of NTDs. Soon thereafter, Laurence et al. ${ }^{2}$ performed a randomized controlled double-blinded study of preconceptional folate treatment and its effect on recurrence of NTDs. There were no recurrences among the 44 women who received folate, whereas among the 51 who received placebo and 6 in the treatment group who did not comply, there were six recurrences. The difference was statistically significant. In the early 1980s, The British Medical Research Council undertook a larger randomized trial to investigate whether the effect of folic acid or other vitamins could reduce the recurrence of NTDs. The results were published in $1991^{3}$ and demonstrated a $72 \%$ reduction in recurrence risk in those who consumed folic acid before conception. Two other controlled trials also showed a reduction in recurrence risk, with the pooled reduction in risk among those who were compliant was $87 \%{ }^{4}$ In the meantime, or soon thereafter, several other studies were done to investigate the correlation between either folic acid or multivitamins containing folic acid and occurrence of NTDs. Most of these were case-control studies, one was a cohort study, and one was a randomized controlled trial. Most of the case-control studies found a correlation between low folate levels and occurrence of NTDs, ${ }^{5-8}$ with odds ratios between 0.4 and 0.65 . One of the studies ${ }^{6}$ stratified odds ratios by amount of folate ingested and showed decreasing risk with increasing folate, with odds ratios ranging between 0.94 and 0.38 (although all of the confidence intervals included 1). However, two other studies ${ }^{9,10}$ did not find a difference between cases and controls; the reasons for this are not clear (but could be related to the background NTD rate, recall bias in other studies, etc.). The cohort study ${ }^{11}$ determined the prevalence ratio between a low folate group $(<100 \mu \mathrm{g})$ and a high folate group ( $\geq 100 \mu \mathrm{g}$ ). The prevalence ratio was 0.29 . However, it should be noted that among the 49 cases with a NTD, 6 had either multiple congenital anomalies or a chromosome anomaly. It is unknown in which group these occurred. Most definitive, however, was the randomized controlled trial, ${ }^{12}$ which compared the frequency of NTD in the multivitamin-supplemented 
group (with the multivitamin containing $0.8 \mathrm{mg}$ of folic acid) with the nonsupplemented group. There were no occurrences in the supplemented group ( $N=2104$ pregnancies $)$ and six in the nonsupplemented group $(N=2052)$, which was statistically significant $(P=0.029)$.

However, it is clear that nearly half of pregnancies are unplanned ${ }^{13}$; in addition, compliance has been found to be fairly poor in various studies. Byrne et al. ${ }^{14}$ found that only $58 \%$ of the aunts of affected children used supplements before pregnancy; Rinsky-Eng and Miller ${ }^{15}$ found that $53 \%$ of mothers of affected children did not know about the recommended use of folates before pregnancy; and Wilton and Foureur ${ }^{16}$ found that only $34.5 \%$ of women with a planned pregnancy used supplements before conception. As a result, the United States and several other countries instituted folic acid fortification of foods, with the US policy of fortifying enriched grain products with $140 \mu \mathrm{g} / 100 \mathrm{~g}$ of folic acid becoming a mandate as of January 1 , 1998.

Since the institution of fortification, numerous studies have examined the frequency of NTDs both in the United States and in other countries in which fortification was mandated. In the United States, the reduction in frequency of NTDs was approximately $31 \%$ for spina bifida and $16 \%$ for anencephaly. ${ }^{17}$ In Chile, which added $220 \mu \mathrm{g} / \mathrm{kg}$ folic acid to wheat flour, the prevalence of NTDs declined from 17.5 to 8 cases per 10,000 births, a $46 \%$ reduction. ${ }^{18}$ In Australia where voluntary fortification began in 1995 , there has been a $32 \%$ reduction in the frequency of anencephaly, a 34\% reduction in the frequency of encephalocele, and a $23 \%$ reduction in the frequency of spina bifida. ${ }^{19}$ In Canada, the level of fortification of flour or cornmeal was $150 \mu \mathrm{g} / 100 \mathrm{~g}$, and of rice, as high as $308 \mu \mathrm{g} / 100 \mathrm{~g}$, with a postfortification reduction in NTD frequency of $46 \%$. However, there is marked geographic variation in Canada, and as a result, the magnitude of the decrease was proportional to the prefortification baseline risk in each province, so that geographic differences in risk disappeared postfortification. ${ }^{20}$ Finally, Bol et al. ${ }^{21}$ found, via a retrospective cohort study, that infants with spina bifida who were born after fortification had a significantly better first-year survival rate than did infants with spina bifida born before the era of fortification. In general, the decrease in risk has been disappointing, leading some groups to recommend an increase in the amount of folic acid added to foods. ${ }^{22}$

However, not all countries have been as willing to embrace fortification. For example, in Finland, mandatory fortification is not permitted, citing as the reason the need to determine possible risks of fortification. This raises several questions that should be addressed before additional fortification is undertaken.

1. What are other benefits of folate supplementation or fortification?

Numerous studies have suggested that other major anomalies (e.g., cleft lip/palate, cardiac defects, and renal anomalies) may be caused by folate deficiency, and if so, folic acid supplementation could reduce the frequency of those anomalies. However, results are conflicting. Botto et al. ${ }^{23}$ reviewed data from 15 birth defects registries and surmised that, in general, there was a lack of reduction in frequencies of several birth defects after supplementation or fortification programs, with the exception of a decreased frequency of cleft lip/palate in postfortification in Atlanta. Godwin et al. ${ }^{24}$ compared the frequencies of the birth prevalence of several anomalies prefortification with postfortification in Canada. They found a decreased frequency of atrial septal defects, no change in the frequency of other cardiac anomalies, cleft lip/palate, cleft palate, or limb defects, and an increased frequency of obstructive renal anomalies, gastroschisis, and pyloric stenosis. Finally, Czeizel ${ }^{25}$ reported that as part of the randomized controlled trial investigating the effect of multivitamin supplementation on NTD frequency, and a subsequent cohort-controlled trial comparing outcomes in supplemented versus nonsupplemented women, it was found that urinary tract anomalies and cardiovascular defects showed a statistically significant reduction in frequency (although confidence intervals included 1 for the odds ratio of urinary tract abnormalities). The frequency of cleft lip/palate did not show a reduction in either group. It can therefore be concluded that there is no strong evidence that folic acid supplementation or fortification is associated with a significant decrease in the frequency of non-NTD congenital anomalies.

Studies have also investigated the effect of folate supplementation on other conditions. In brief, slightly reduced frequencies of pancreatic cancer in females, prostate cancer, and possibly colon cancer have been described, as has a possible folateassociated decrease in hearing loss in the elderly. ${ }^{26-29}$

\section{What are potential hazards of folate supplementation or fortification?}

Increased folate consumption is not without potential hazards. The main stated complication of increased folate is the masking of megaloblastic anemia caused by vitamin B12 deficiency. This is generally not an issue for women of reproductive age but becomes a concern for those older than 65 years. ${ }^{30}$

In addition, a slightly increased risk of wheeze and respiratory tract infections was found in offspring whose mothers took folic acid supplements during pregnancy. ${ }^{31}$ Yajnik et al. ${ }^{32}$ reported that children whose mothers had high folate and low vitamin B12 levels during pregnancy had the highest risk of insulin-resistance, compared with those whose mothers who only had low B12 or high folate (but both of those groups had higher levels than did those whose mothers had normal B12 and folate). Increased folate levels have also been associated with increased lung cancer risk ${ }^{33}$; reduced natural killer cell cytotoxicity ${ }^{34}$; and, in the presence of concomitant low B12, anemia and cognitive impairment in the elderly. ${ }^{35}$ It has been suggested that there may be increased risk for certain cancers in the presence of high folate levels, although there is no clear evidence confirming these observations. ${ }^{36}$

\section{What is the appropriate amount of folic acid? Do we need more?}

Given the concerns about unnecessary exposure to increased levels of folic acid, it is important to determine the amount necessary to prevent NTDs, without exposing the rest of the population to potentially hazardous amounts. The initial recommendations that women of childbearing age receive $400 \mu \mathrm{g} /$ day were apparently based on the fact that it was the amount available in multivitamin supplements. ${ }^{37}$ This amount raised red cell folate levels to 571 (481-654) $\mu \mathrm{g} / \mathrm{L} .{ }^{38}$ Given the recommendation that red cell folate should be at least $400 \mu \mathrm{g} / \mathrm{L}$, Daly et al. ${ }^{38}$ determined that in a randomized controlled trial, delivery of $200 \mu \mathrm{g}$ daily was sufficient to increase all of the women's red cell folate levels to $400 \mu \mathrm{g} / \mathrm{L}$. This is important because it has been established the tolerable upper limit in children aged 1-3 years is $300 \mu \mathrm{g} / \mathrm{day}$, and for children aged $4-8$ years, the tolerable upper limit is $400 \mu \mathrm{g} /$ day. ${ }^{39}$ In addition, Shakur et al. ${ }^{40}$ have found that the actual content of folic acid in fortified food was $50 \%$ higher than what was stated on the label. Finally, it is possible that the postfortification NTDs are folate resistant and 
that further fortification will not be necessary. Mosley et al. ${ }^{41}$ did a case-control study in which cases and controls were sorted in quartiles in terms of folic acid supplementation use and dietary folate intake. There was no difference between cases and controls for any of the quartiles, suggesting that even at the lowest levels of intake, the amount of folic acid that was ingested was sufficient to prevent folate-sensitive NTDs. There is therefore insufficient evidence to suggest that increased fortification by folic acid is warranted, particularly in light of potential risks to other segments of the population.

\section{Are there other nutrients that could further reduce risks of NTDs?}

There is some preliminary evidence that vitamin B12 might also be involved in the cause of NTDs. A few studies and literature reviews have reported that either in the postfortification era or in studies in which folate level was a constant, lower levels of B12 were associated with a higher risk of NTDs. ${ }^{42-45}$ However, all urged caution before supplementing the diet with $\mathrm{B} 12$, for various reasons. Ideally, a randomized controlled trial would be ideal to better address the question of how much of a reduction in NTDs would occur secondary to B12 supplementation. In addition, B12 is not found in cereal products, and so information would need to be obtained regarding how best to fortify foods with B12.44 In addition, in older populations, vitamin B12 deficiency is related to malabsorption rather than intake, and so it is uncertain whether fortification would be useful for these individuals. ${ }^{46}$

Another nutrient that has also been associated with NTDs is choline. Shaw et al. ${ }^{47}$ found that in a folate-fortified population, lower levels of choline were associated with higher risks of NTDs. However, here again, replication studies should be done before proceeding with food fortification of choline. In conclusion, B12 and/or choline supplementation and/or fortification may be helpful in further reducing the incidence of NTDs; however, there needs to be further study to determine the efficacy and appropriate means of providing the required amount to the target populations.

Given the above information, what have other groups recommended? The American Academy of Pediatrics committee on genetics issued its guidelines in 199948 and included the recommendations that all women capable of becoming pregnant should consume $0.4 \mathrm{mg}$ of folic acid per day; that if there has been a previously affected pregnancy, $4 \mathrm{mg} /$ day, commencing before conception, be consumed; that high-risk groups (women with a positive family history, type 1 diabetes mellitus, seizure disorders treated with valproate or carbamazepine, or who themselves have a NTD) also consume $4 \mathrm{mg}$ /day; that educational programs be developed to promote folic acid consumption; and that fortification should attempt to provide all women capable of becoming pregnant with a daily intake of $0.4 \mathrm{mg} /$ day. The American College of Obstetricians and Gynecologists issued its practice guideline in 2003 and had very similar recommendations, including $0.4 \mathrm{mg}$ for all women and $4 \mathrm{mg}$ for women at higher risk. ${ }^{49}$ The joint Society of Obstetricians and Gynaecologists of Canada and Motherisk guideline ${ }^{50}$ had 10 components to their practice guideline. These were to recommend (1) education for all women of reproductive age about folate, (2) women maintain a healthy diet, (3) consumption of only one dose of a multivitamin, (4) that folic acid and multivitamins be widely available, (5) that $5 \mathrm{mg}$ be given to not only prevent recurrence of NTDs but also cleft lip/palate, heart defects, limb defects, urinary tract abnormalities, and hydrocephalus, (6) that $5 \mathrm{mg}$ of folic acid will not mask vitamin B12 deficiency, (7) primary prevention could be accomplished in one of three ways, with $0.4-1 \mathrm{mg} /$ day from vitamins and food, or $5 \mathrm{mg}$ /day for high-risk groups (including certain ethnic groups) or those who have a poor lifestyle or evidence of poor compliance with medication use, (8) increased food fortification to $300 \mu \mathrm{g} / 100 \mathrm{~g}$ flour, (9) the Canadian government consider increasing fortification with other vitamins, and (10) the organization of a consensus conference on the use of folic acid and multivitamins for the prevention of congenital anomalies. Finally, United States Preventive Services Task Force has recently issued an updated guideline on the use of folic acid supplementation to prevent NTD. This was an evidence-based review and concluded that all women planning or capable of pregnancy should take a daily supplement containing $0.4-0.8 \mathrm{mg}$ folic acid. This was a Grade A recommendation (high certainty that the net benefit is substantial). ${ }^{51}$

\section{AMERICAN COLLEGE OF MEDICAL GENETICS RECOMMENDATIONS}

1. All women capable of becoming pregnant should strive for intake of $400 \mu \mathrm{g}(0.4 \mathrm{mg})$ of folic acid daily, in the form of a supplement, multivitamin, consumption of fortified foods, or a combination of the above. This is particularly important before conception and throughout the first trimester of pregnancy.

2. Women who have had a previous NTD-affected pregnancy, who are themselves affected, have a first- or second-degree relative with a NTD, or who have diabetes mellitus type 1 may be advised to take $4 \mathrm{mg}$ of folic acid commencing 3 months before conception and continuing throughout the first trimester. However, they should seek genetic counseling to determine their occurrence or recurrence risks, pregnancy management, and the appropriate folic acid intake for them.

3. There should be increased public health efforts to increase awareness of the role of folic acid in reducing the incidence of NTDs.

4. Studies have produced conflicting or inconclusive results about the risks and benefits of increasing fortification of foods with folic acid or other foods; therefore, there is no evidence to support such fortification. We do recommend that additional study be done to better determine the risks and benefits for the entire population.

\section{REFERENCES}

1. Smithells RW, Sheppard S, Schorah CJ. Vitamin deficiencies and neural tube defects. Arch Dis Child 1976;51:944-950.

2. Laurence KM, James N, Tennant GB, Campbell H. Double-blind randomised controlled trial of folate treatment before conception to prevent recurrence of neural-tube defects. Br Med J (Clin Res Ed) 1981;282:15091511.

3. MRC Vitamin Study Research Group. Prevention of neural tube defects: results of the Medical Research Council Vitamin Study. Lancet 1991;338: $131-137$.

4. Grosse SD, Collins JS. Folic acid supplementation and neural tube defect recurrence prevention. Birth Def Res A Clin Mol Teratol 2007;79:737-742.

5. Mulinare J, Cordero JF, Erickson JD, Berry RJ. Periconceptional use of multivitamins and the occurrence of neural tube defects. JAMA 1988;260: 3141-3145.

6. Bower C, Stanley FJ. Dietary folate as a risk factor for neural-tube defects: evidence from a case-control study in Western Australia. Med J Aust 1989; 150:613-619.

7. Werler MM, Shapiro S, Mitchell AA. Periconceptional folic acid exposure and risk of occurrent neural tube defects. JAMA 1993;269:1257-1261.

8. Shaw GM, Schaffer D, Velie EM, Morland K, Harris JA. Periconceptional vitamin use, dietary folate, and the occurrence of neural tube defects. Epidemiology 1995;6:219-226.

9. Mills JL, Rhoads GG, Simpson JL, et al. The absence of a relationship 
between the periconceptional use of vitamins and neural-tube defects. National Institute of Child Health and Human Development Neural Tube Defects Study Group. N Engl J Med 1989;321:430-435.

10. Mills JL, Tuomilehto J, Yu KF, et al. Maternal vitamin levels during pregnancies producing infants with neural tube defects. J Pediatr 1992;120: $863-871$.

11. Milunsky A, Jick H, Jick SS, et al. Multivitamin/folic acid supplementation in early pregnancy reduces the prevalence of neural tube defects. JAMA 1989;262:2847-2852.

12. Czeizel AE, Dudas I. Prevention of the first occurrence of neural-tube defects by periconceptional vitamin supplementation. N Engl J Med 1992; 327:1832-1835.

13. Trussell J. The cost of unintended pregnancy in the United States. Contraception 2007;75:168-170.

14. Byrne J, Byrne C, Collins D. Trends in periconceptional folic acid use by relatives in Irish families with neural tube defects. Ir Med J 2001;94:302305.

15. Rinsky-Eng J, Miller L. Knowledge, use and education regarding folic acid supplementation: continuation study of women in Colorado who had a pregnancy affected by a neural tube defect. Teratology 2002;66:S29-S31.

16. Wilton DC, Foureur MJ. A survey of folic acid use in primigravid women. Women Birth 2010;23:67-73.

17. Williams LJ, Mai CT, Edmonds LD, et al. Prevalence of spina bifida and anencephaly during the transition to mandatory folic acid fortification in the United States. Teratology 2002;66:33-39.

18. Lopez-Camelo JS, Orioli IM, da Graca Dutra M, et al. Reduction of birth prevalence rates of neural tube defects after folic acid fortification in Chile. Am J Med Genet 2005; 135:120-125.

19. Bower C, D'Antoine H, Stanley FJ. Neural tube defects in Australia: trends in encephaloceles and other neural tube defects before and after promotion of folic acid supplementation and voluntary food fortification. Birth Def Res A Clin Mol Teratol 2009; 85:269-273.

20. De Wals P, Tairou F, Van Allen MI, et al. Reduction in neural-tube defects after folic acid fortification in Canada. $N$ Engl J Med 2007;357:135-142.

21. Bol KA, Collins JS, Kirby RS; National Birth Defects Prevention Network. Survival of infants with neural tube defects in the presence of folic acid fortification. Pediatrics 2006;117:803-813.

22. Johnston RB Jr. Will increasing folic acid in fortified grain products further reduce neural tube defects without causing harm?: consideration of the evidence. Pediatr Res 2008; 63:2-8.

23. Botto LD, Lisi A, Bower C, et al. Trends of selected malformations in relation to folic acid recommendations and fortification: an international assessment. Birth Defects Res A Clin Mol Teratol 2006;76:693-705.

24. Godwin KA, Sibbald B, Bedard T, Kuzeljevic B, Lowry RB, Arbour L. Changes in frequencies of select congenital anomalies since the onset of folic acid fortification in a Canadian birth defect registry. Can J Publ Health 2008;99:271-275.

25. Czeizel AE. Periconceptional folic acid and multivitamin supplementation for the prevention of neural tube defects and other congenital abnormalities. Birth Def Res A Clin Mol Teratol 2009;85:260-268

26. Oaks BM, Dodd KW, Meinhold CL, Jiao L, Church TR, StolzenbergSolomon RZ. Folate intake, post-folic acid grain fortification, and pancreatic cancer risk in the prostate, lung, colorectal, and ovarian screening trial. Am J Clin Nutr 2010;91:449-455.

27. Shannon J, Phoutrides E, Palma A, et al. Folate intake and prostate cancer risk: a case-control study. Nutr Cancer 2009;61:617-628.

28. Roswall N, Olsen A, Christensen J, Dragsted LO, Overvad K, Tjønneland A. Micronutrient intake and risk of colon and rectal cancer in a Danish cohort. Cancer Epidemiol 2010;34:40-46.

29. Durga J, Verhoef P, Anteunis LJ, Schouten E, Kok FJ. Effects of folic acid supplementation on hearing in older adults: a randomized, controlled trial. Ann Intern Med 2007;146:1-9.

30. Cuskelly GJ, Mooney KM, Young IS. Folate and vitamin B12: friendly or enemy nutrients for the elderly. Proc Nutr Soc 2007;66:548-558

31. Hagberg SE, London SJ, Stigum H, Nafstad P, Nystad W. Folic acid supplements in pregnancy and early childhood respiratory health. Arch Dis Child 2009;94:180-184.

32. Yajnik CS, Deshpande SS, Jackson AA, et al. Vitamin B12 and folate concentrations during pregnancy and insulin resistance in the offspring: the Pune Maternal Nutrition Study. Diabetologia 2008;51:29-38.

33. Ebbing M, Bonaa $\mathrm{KH}$, Nygard $\mathrm{O}$, et al. Cancer incidence and mortality after treatment with folic acid and vitamin B12. JAMA 2009;302:2119-2126.

34. Troen AM, Mitchell B, Sorensen B, et al. Unmetabolized folic acid in plasma is associated with reduced natural killer cell cytotoxicity among postmenopausal women. J Nutr 2006;136:189-194.

35. Selhub J, Morris MS, Jacques PF, Rosenberg IH. Folate-vitamin B-12 interaction in relation to cognitive impairment, anemia, and biochemical indicators of vitamin B-12 deficiency. Am J Clin Nutr 2009; 89(suppl): 702S-706S.

36. Sauer J, Mason JB, Choi SW. Too much folate: a risk factor for cancer and cardiovascular disease? Curr Opin Clin Nutr Metab Care 2009;12:30-36.

37. Rosenberg I. Getting folic acid nutrition right. Am J Clin Nutr 2010;91:3-4.

38. Daly S, Mills JL, Molloy AM, et al. Minimum effective dose of folic acid for food fortification to prevent neural-tube defects. Lancet 1997;350:16661669.

39. Rader JI, Schneeman BO. Prevalence of neural tube defects, folate status, and folate fortification of enriched cereal-grain products in the United States. Pediatrics 2006;117:1394-1399.

40. Shakur YA, Rogenstein C, Hartman-Craven B, Tarasuk V, O'Connor DL. How much folate is in Canadian fortified products 10 years after mandatory fortification? Canad J Publ Health 2009;100:281-284.

41. Mosley BS, Cleves MA, Siega-Riz AM, et al. Neural tube defects and maternal folate intake among pregnancies conceived after folic acid fortification in the United States. Am J Epidemiol 2009;169:9-17.

42. Ray JG, Wyatt PR, Thompson MD, et al. Vitamin B12 and the risk of neural tube defects in a folic-acid-fortified population. Epidemiology 2007;18:362366.

43. Molloy AM, Kirke PN, Troendle JF, et al. Maternal vitamin B12 status and risk of neural tube defects in a population with high neural tube defect prevalence and no folic acid fortification. Pediatrics 2009;123:917-923

44. Thompson MD, Cole DE, Ray JG. Vitamin B-12 and neural tube defects: the Canadian experience. Am J Clin Nutr 2009;89:697S-701S

45. Li F, Watkins D, Rosenblatt DS. Vitamin B(12) and birth defects. Mol Genet Metab 2009;98:166-172.

46. Green R. Is it time for vitamin B-12 fortification? What are the questions? Am J Clin Nutr 2009;89:712S-716S.

47. Shaw GM, Finnell RH, Blom HJ, et al. Choline and risk of neural tube defects in a folate-fortified population. Epidemiology 2009;20:714-719.

48. American Academy of Pediatrics. Committee on Genetics. Folic acid for the prevention of neural tube defects. Pediatrics 1999;104:325-327.

49. Cheschier N; ACOG Committee on Practice Bulletins-Obstetrics. ACOG practice bulletin 44. Neural tube defects. Int J Gynecol Obstet 2003;83:123-133.

50. Wilson RD, Johnson JA, Wyatt P, et al. Pre-conceptional vitamin/folic acid supplementation 2007: the use of folic acid in combination with a multivitamin supplement for the prevention of neural tube defects and other congenital anomalies. J Obstet Gynaecol Can 2007;29:1003-1026.

51. US Preventive Services Task Force. Folic acid for the prevention of neural tube defects: U.S. Preventive Services Task Force recommendation statement. Ann Intern Med 2009;150:626-631. 